(1)

CrossMark

\title{
Current smoking is not associated with COVID-19
}

To the Editor:

We have read with interest the paper by LEung et al. [1] recently published in the European Respiratory Journal, reporting a higher expression of the protein angiotensin-converting enzyme II (ACE-2) in the small airway epithelia of smokers and COPD patients with putatively important implications for coronavirus disease 2019 (COVID-19) patients, since ACE-2 has been shown to be the receptor utilised by severe acute respiratory syndrome coronavirus 2 (SARS-CoV-2) to enter the host cell [2]. Furthermore, the authors reported that current smokers showed a higher expression of ACE-2 gene expression than non-smokers, concluding that the increased ACE-2 expression in smokers might predispose to increased risk of SARS-CoV-2 infection [1].

To this regard, all epidemiological data published so far reported that COVID-19 patients show a very low prevalence of smokers, with no significant association between current smoking and severe disease in COVID-19 patients [3-6].

At the University-Hospital of Padova, located in the Veneto Region, one of the areas in Italy most affected by COVID-19, between 15 March and 10 April, 2020, 132 patients were assessed in our clinic for SARS-CoV-2 related pneumonia. The analysis of patients' smoking history showed that no-one was a current smoker, with 112 patients (84.8\%) who had never smoked and 20 (15.2\%) who were former smokers. These data are in agreement with those from China [3-6]. Furthermore, there was no difference in the disease severity between patients who never smoked and former smokers. These data are even more striking if we consider that the percentage of current smokers in Italy and in the Veneto Region is $25.7 \%$ and $22.7 \%$, respectively (www.epicentro.iss.it/passi/dati/fumo).

Thus, the conclusions of LEUNG et al. [1] to consider cigarette smoking as a severe risk factor for COVID-19 pneumonia are in contrast with the strong and consolidated epidemiological data coming from China [3-6] that have been confirmed also in our patients.

@ERSpublications

Despite the main complications of SARS-CoV-2 infection regard lung involvement, the prevalence of current smoking in COVID-19 patients is very low, thus questioning the role of coexisting active smoking as a risk factor for COVID-19 pneumonia https://bit.ly/3eUnl1R

Cite this article as: Rossato M, Russo L, Mazzocut S, et al. Current smoking is not associated with COVID-19. Eur Respir J 2020; 55: 2001290 [https://doi.org/10.1183/13993003.01290-2020].

Marco Rossato (D), Lucia Russo, Sara Mazzocut, Angelo Di Vincenzo, Paola Fioretto and Roberto Vettor Clinica Medica 3, Dept of Medicine - DIMED, University-Hospital of Padova, Padova, Italy.

Correspondence: Marco Rossato, Clinica Medica 3, Dept of Medicine - DIMED, University-Hospital of Padova, Via Giustiniani, 2, 35128 Padova, Italy. E-mail: marco.rossato@unipd.it

Received: 20 April 2020 | Accepted after revision: 22 April 2020

Conflict of interest: None declared.

\section{References}

1 Leung JM, Yang CX, Tam A, et al. ACE-2 expression in the small airway epithelia of smokers and COPD patients: implications for COVID-19. Eur Resp J 2020; 55: 2000688.

2 Hoffmann M, Kleine-Weber H, Schroeder S, et al. SARS-CoV-2 cell entry depends on ACE2 and TMPRSS2 and is blocked by a clinically proven protease inhibitor. Cell 2020; 181: 271-280.

3 Guan WJ, Ni ZY, Hu Y, et al. Clinical characteristics of coronavirus disease 2019 in China. N Engl J Med 2020; 382: 1708-1720.

4 Guan WJ, Liang WH, Zhao Y, et al. Comorbidity and its impact on 1590 patients with COVID-19 in China: a nationwide analysis. Eur Respir J 2020; 55: 2000547.

5 Emami A, Javanmardi F, Pirbonyeh N, et al. Prevalence of underlying diseases in hospitalized patients with COVID-19: a systematic review and meta-analysis. Arch Acad Emerg Med 2020; 8: e35. 

Intern Med 2020; 75: 107-108.
Copyright (CERS 2020.

This version is distributed under the terms of the Creative Commons Attribution Non-Commercial Licence 4.0.

\title{
Reply to: "Current smoking is not associated with COVID-19"
}

\author{
From the authors:
}

Like M. Rossato and co-workers, we too have been struck by the relative underrepresentation of current smokers in cohorts of coronavirus disease 2019 (COVID-19) patients, particularly in light of our recent findings that the severe acute respiratory syndrome coronavirus 2 (SARS-CoV-2) receptor angiotensin-converting enzyme II (ACE-2) is upregulated in the airway epithelium of this population [1]. China [2], Italy (as reported by M. Rossato and co-workers), and now New York City [3] have all reported current smoking rates below those of their respective general populations. The reason for this is a mystery. One possible explanation is misclassification of smoking status owing to under-reporting of smoking in these cohorts. Another is that smokers may be taking medications that may offer some protection against COVID-19 (e.g. certain inhalers). It should be noted that severe COVID-19 preferentially targets the older population ( $>65$ years) with comorbidities, in whom smoking rates are approximately $3-5$ fold lower than that in the general population. Thus, the background smoking rates in the severe COVID-19 susceptible subgroups may be much lower than the general smoking rates of the population. Notwithstanding these issues, we should be extraordinarily cautious about the messaging surrounding smoking and COVID-19, especially in these fraught times where misinformation is commonly amplified in a vacuum of rigorous evidence $[4,5]$. We are unaware of any evidence to date that demonstrates that smoking is protective against COVID-19. In fact, although current smoking has not been found to be a major risk factor for COVID-19, COPD patients appear to have worse outcomes upon contracting the virus with an almost threefold odds ratio of dying, needing mechanical ventilation, or being admitted to an intensive care unit [6]. As many of our COPD patients in this pandemic fit an unfavourable demographic profile - elderly, male, and with cardiovascular comorbidities - we would continue to recommend exercising caution in protecting them from COVID-19.

@ERSpublications

Smoking and COPD are risk factors for severe COVID-19 https://bit.ly/2KJxAbp

Cite this article as: Leung JM, Yang CX, Sin DD. Reply to: "Current smoking is not associated with COVID-19”. Eur Respir J 2020; 55: 2001340 [https://doi.org/10.1183/13993003.01340-2020].

Janice M. Leung ${ }^{1,2}$, Chen Xi Yang ${ }^{1}$ and Don D. $\operatorname{Sin}^{1,2}$

${ }^{1}$ Centre for Heart Lung Innovation, University of British Columbia, Vancouver, BC, Canada. ${ }^{2}$ Division of Respiratory Medicine, Dept of Medicine, St Paul's Hospital, Vancouver, BC, Canada.

Correspondence: Don D. Sin, Division of Respiratory Medicine, Dept of Medicine, St. Paul's Hospital, 1081 Burrard Street, Vancouver, BC V6Z1Y6, Canada. E-mail: Don.Sin@hli.ubc.ca

Received: 22 April 2019 | Accepted: 23 April 2019

Conflict of interest: J.M. Leung has nothing to disclose. C.X. Yang has nothing to disclose. D.D. Sin reports grants from Merck, Boehringer Ingelheim, personal fees for advisory board work from Sanofi-Aventis, Regeneron, grants and personal fees for advisory board work and lectures from AstraZeneca, personal fees for advisory board work and lectures from Novartis, outside the submitted work.

\section{References}

1 Leung JM, Yang CX, Tam A, et al. ACE-2 expression in the small airway epithelia of smokers and COPD patients: implications for COVID-19. Eur Resp J 2020; 55: 2000688.

2 Guan WJ, Ni ZY, Hu Y, et al. Clinical characteristics of coronavirus disease 2019 in China. N Engl J Med 2020; 382: $1708-1720$.

3 Goyal P, Choi JJ, Pinheiro LC, et al. Clinical characteristics of Covid-19 in New York City. N Engl J Med 2020; in press [https://doi.org/10.1056/NEJMc2010419]. 
Garrett L. COVID-19: the medium is the message. Lancet 2020; 395: 942-943.

Zarocostas J. How to fight an infodemic. Lancet 2020; 395: 676 .

6 Guan WJ, Liang WH, Zhao Y, et al. Comorbidity and its impact on 1590 patients with COVID-19 in China: a nationwide analysis. Eur Respir J 2020; 55: 2000547.

Copyright CERS 2020.

This version is distributed under the terms of the Creative Commons Attribution Non-Commercial Licence 4.0. 